Gabrijela Petra Nagode

gabrijela.nagode@gmail.com

\section{Karmen Pižorn}

Pedagoška fakulteta Univerze v Ljubljani

karmen.pizorn@pef.uni-lj.si
UDK 81'243:37.091.3

DOI: 10.4312 /vestnik.8.203-215

\title{
MITI O UČENJU DRUGEGA/TUJEGA JEZIKA
}

1

UVOD

O učenju tujih jezikov obstajajo določeni miti, nepreverjene »resnice«, ki so se ponekod »fosilizirali« in morda sploh več ne vzbujajo nobenih dvomov med običajnimi uporabniki jezikov. Članek spodbuja bralca k preverjanju pogledov na učenje drugega/tujega jezika, kar se zdi potrebno, saj je s prepričanji povezan tudi način poučevanja. Predstavljeni so štirje miti o učenju drugega/tujega jezika, izbrani iz nabora osemnajstih mitov, obravnavanih v osnovni literaturi članka s področja učenja jezikov. Odločitev o ožjem izboru temelji na strokovni pedagoški presoji avtoric. Prvi mit obravnava vlogo starosti pri učenju drugega/tujega jezika. Čim zgodnejši začetek učenja drugega/tujega jezika ne vodi nujno $k$ večji uspešnosti. Uspešnost je relativna glede na končni cilj. Če je tradicionalno merilo uspešnosti glede na raziskave bila zgolj izgovarjava, ki naj bi se čim bolj približala tisti naravnega govorca, je po novejših raziskavah merilo lahko, na primer, skladnja. Na uspešnost poleg starosti vplivajo tudi čas in trud, vložen v učni proces, motiviranost, stopnja tesnobnosti, spretnosti sprejemanja in tvorjenja jezika ter dejavniki učnega okolja (kontekst). Drugi mit obravnava problematiko pozitivnega in negativnega prenašanja znanja prvega jezika v drugi/tuji jezik, kar imenujemo transfer. Če napake nastanejo zaradi želje učencev po samostojnem raziskovanju ciljnega jezika, niso posledica transferja. Tretji mit obravnava učiteljev odnos do napak. Napaka je lahko vir informacij o vrzelih v znanju, prekomernem upoštevanju pravil v drugem/tujem jeziku, neustreznem prenašanju (transfer) vzorcev iz prvega jezika v drugi/tuji jezik. Povratna informacija je potrebna, vendar je pomemben način. Četrti mit obravnava vlogo branja pri širjenju besedišča. Učenci naj bi brali različne vrste besedil, tako predpisane kot za zabavo. Besedila naj bi bila vsakemu posameznemu bralcu zanimiva in pomembna. 
Mit 1: Čim prej se začnemo učiti drugega/tujega jezika, tem bolj bomo pri učenju uspešni.

Vprašanje smiselnosti čim bolj zgodnjega začetka učenja tujega jezika je kompleksno, zato je potrebno imeti v mislih različne okoliščine oziroma dejavnike, ko želimo ta mit potrditi ali ovreči.

Odločitev o tem, pri kateri starosti uvesti pouk drugega/tujega jezika v svetu kot tudi pri nas, mora temeljiti na cilju jezikovnega programa in družbenega konteksta šole (Lightbown in Spada, 2005, str. 97). Poleg postavljenega cilja so potrebni tudi ustrezni pogoji za učenje drugega/tujega jezika, kot je dovolj velika izpostavljenost učencev jeziku ter možnosti uporabe jezika v različnih kontekstih (Lightbown in Spada, 2013, str. 204-5). V programih, namenjenih doseganju ravni rojstnih govorcev pri vseh (čim več) učencih, je zgodnejši začetek morda bolj smiseln kot v programih z nižje zastavljenim končnim ciljem (Lightbown in Spada, 2005, str. 97). Končni cilj je zastavljen različno visoko tudi glede na to, ali gre za prvi tuji jezik, drugi oziroma nadaljnji tuji jezik.

V Sloveniji naj bi učenci ob koncu osnovne šole pri angleščini kot prvem tujem jeziku dosegli raven A2/A2+ pri vseh štirih jezikovnih zmožnostih (poslušanju, branju, govoru in pisanju) (Svet Evrope, 2011 ${ }^{1}$; Lesničar, 2016). Ta cilj podpira 656 ur pouka $\mathrm{v}$ drugem in tretjem triletju ter dodatnih 70 ur v drugem in tretjem razredu (Pevec Semec, 2013b), v zadnjem času pa še 70 ur angleščine kot neobveznega izbirnega predmeta $\mathrm{v}$ prvem razredu osnovne šole (Pevec Semec, 2013a).

Naši učenci so leta 2012 ob koncu devetletke v mednarodni raziskavi SurveyLang (European Commission, 2012, str. 8) dosegli sledeče rezultate. Pri branju 12\% učencev ni doseglo ravni A1, $42 \%$ učencev je doseglo raven razpona $A, 47 \%$ pa raven razpona B. Pri poslušanju 5\% učencev ni doseglo ravni A1, 28\% jih je doseglo raven razpona $\mathrm{A}$, $67 \%$ pa raven razpona B. Pri pisanju 1\% učencev ni dosegel ravni A1, 51\% učencev je doseglo raven razpona A, 48\% pa raven razpona $\mathrm{B}$. Raziskava ni zajela govora. Postavlja se vprašanje o ustreznosti kvote ur pouka glede na cilj.

Vendar pa je lahko končni cilj izobraževanja drugega/tujega jezika tudi nižji in sicer doseči raven rojstnih govorcev le pri nekaterih učencih. Končni cilj za vse učence pa je usvojiti zgolj osnovne sporazumevalne spretnosti (ang. basic communicative skills) in

1 Skupni evropski jezikovni okvir (SEJO) predstavlja skupno osnovo za pripravljanje jezikovnih učnih načrtov, kurikularnih smernic, izpitov, učbenikov itn. v Evropi. Podrobno opisuje, česa vse se morajo osebe, ki se učijo jezikov, naučiti, da bodo uporabljale jezik za sporazumevanje, in katera znanja in spretnosti morajo razviti, da bodo lahko učinkovito delovale. Opis zajema tudi kulturni kontekst, v katerega je postavljen jezik. Okvir prav tako opredeljuje ravni jezikovnega znanja, ki omogočajo, da merimo napredek učencev na vsakem koraku učenja in na vseživljenjski osnovi. Pridobljeno 10.5.2016 s http://www.mizs.gov.si/si/delovna_podrocja/urad_za_razvoj_izobrazevanja/jezikovno_izobrazevanje/ skupni_evropski_jezikovni_okvir/ 
utrjevati prvi jezik (v nad. J1). V tem primeru je verjetno smiselno z začetkom učenja drugega/tujega jezika počakati (Lightbown in Spada, 2005, str. 97). Nekatere raziskave (Snow in Hoefnagel-Höhle, 1978) dokazujejo, da starejši otroci, ki se začnejo učiti drugega/tujega jezika kasneje v primerjavi s svojimi vrstniki, te vrstnike v znanju hitro dohitijo, tudi če program obsega le nekaj ur pouka tedensko. Napredek je še hitrejši, če so nekaj časa drugemu/tujemu jeziku intenzivno izpostavljeni (Lightbown in Spada, 2013, str. 97). Hkrati pa je potrebno opozoriti, da se še posebej pri starejših učencih kaže, da uspeh pri učenju drugega/tujega jezika ni odvisen le od starosti, pri kateri so se ga začeli učiti, pač pa tudi od jezikovne učljivosti, kar po Carrollu (1991) razumemo kot sposobnost hitrega učenja, motiviranosti, ustreznih družbenih pogojev za učenje (Lightbown in Spada, 2005, str. 99) in od znanja sorodnih jezikov. Torej odločitev o tem, kdaj je najprimernejši čas za začetek učenja drugega/tujega jezika, ne more temeljiti le na hipotezi o obdobju posebne dojemljivosti oziroma odprtosti mlajšega učenca za učenje jezikov (Lightbown in Spada, 2013, str. 96). Ta se namreč osredotoča le na starost in doseganje obvladovanja na ravni rojstnih govorcev. Upoštevati je potrebno še izobraženost učiteljev, tako jezikovno kot tudi didaktično, pa tudi število ur izpostavljenosti jeziku izven pouka.

Nekateri učenci ne glede na to, da se drugega/tujega jezika učijo že sedem ali osem let, napredujejo zelo počasi, kar lahko povzroča frustracijo (Lightbown in Spada, 2013, str. 98). Razlog je lahko v premajhnem številu ur pouka drugega/tujega jezika (pomembna je tudi razporejenost ur) ali pa previsoko zastavljenem cilju, doseči raven rojstnih govorcev. Takšni primeri so se pojavili tudi v Kanadi, kjer so pod pritiski staršev prestavili začetek učenja drugega/tujega jezika od 9 na 6 let, število ur pa so le prerazporedili na daljše časovno obdobje (Lightbown in Spada, 2013, str. 97).

Tako izkušnje kot nekatere raziskave kažejo, da zgodnji začetek učenja drugega/ tujega jezika ni nujno garancija za uspeh. Vodilo pri odgovoru na vprašanje, kdaj je najprimernejši čas za to, je končni cilj. Upoštevati je potrebno tudi kontekst, povezan z učenjem drugega/tujega jezika (Lightbown, 2008), kar v formalnem okolju (šolskem) razumemo kot razpoložljiva sredstva.

Glavno merilo obvladovanja drugega/tujega jezika je v raziskavah najpogosteje naglas rojstnega govorca. Večina raziskav povezanosti med starostjo in napredovanjem v drugem/tujem jeziku se torej osredotoča na izgovarjavo kot najpomembnejši razločevalni dejavnik med (ne)obvladovanjem jezika. Te raziskave pogosto ugotavljajo, da učenci, ki se začnejo učiti drugega/tujega jezika kasneje, ne dosežejo cilja govoriti z naglasom rojstnih govorcev (Lightbown in Spada, 2013, str. 94).

Patkowski (1980) za merilo obvladovanja drugega/tujega jezika namesto izgovarjave naravnega govorca kot sicer pogostejšega merila izbere skladnjo in raziskuje njeno povezanost s starostjo. Postavi hipotezo, da lahko le tisti, ki so se začeli učiti drugega/ tujega jezika pred svojim petnajstim letom, dosežejo jezikovno raven rojstnih govorcev. Kot zapisano, tu ni mišljena izgovarjava, pač pa skladnja. V raziskavi primerja skupino priseljencev v ZDA s skupino Američanov, ki se niso priselili. Starost priseljencev 
ob njihovem prihodu v ZDA je bila različna. Vsi so živeli v ZDA že vsaj pet let in so bili visoko izobraženi. Patkowski primerja skupini tudi po drugih napovednih dejavnikih uspešnosti pri obvladovanju drugega jezika. Upošteva skupen čas bivanja v ZDA in število ur pouka angleščine kot drugega jezika (angl. ESL instruction). Glavno raziskovalno vprašanje je, ali se bo pokazala razlika med skupino učencev, ki so se začeli učiti angleščino pred oziroma po puberteti. Patkowski je govorce posnel in njihov govor transkribiral. Izsledki raziskave so pokazali sledeče: skupina, ki se je začela učiti angleščino v predpubertetnem obdobju, je dosegla visoke ocene in je bila precej homogena $\mathrm{v}$ znanju. V drugi skupini pa so bili rezultati (ocene znanja) veliko bolj razpršeni. Zapise so ocenili usposobljeni ocenjevalci z ocenami od 0 za neznanje angleščine do 5 za znanje, ki je dosegalo jezikovno raven izobraženega naravnega govorca. Patkowski je preučil tudi vpliv nekaterih drugih dejavnikov, vendar se je izkazalo, da so bili močno povezani z drugimi dejavniki in jih zato ni bilo mogoče obravnavati ločeno. Ugotovil je, da starost pri tistih, ki se učijo drugega/tujega jezika pretežno v naravnem okolju (ne v šoli), pomembno vpliva na končno doseženo znanje drugega/tujega jezika in sicer ne samo na izgovarjavo.

\section{Vprašanje (ne)obstoja kritičnega obdobja}

Hipoteza o kritičnem obdobju (Lenneberg, 1967) pravi, da obstajajo genetsko pogojena obdobja v razvoju, ko smo za učenje določenih vrst znanja in spretnosti še posebej dojemljivi. J1 naj bi usvojili pred koncem procesa cerebralne lateralizacije/stranskosti, torej približno do začetka pubertete. Po analogiji naj bi se tudi drugega/tujega jezika lahko odlično naučili le pred puberteto. Mnenja znanstvenikov o kritičnem obdobju za učenje drugega/tujega jezika pa so veliko bolj deljena kot mnenja o kritičnem obdobju za J1.

Snow in Hoefnagel-Höhle (1978), na primer, ne podpirata hipoteze o kritičnem obdobju za drugi/tuji jezik. Ugotovila sta, da so učenci, stari med 12 in 15 let ter odrasli, najhitreje napredovali v znanju nizozemščine kot drugega/tujega jezika v začetnih mesecih učenja (ang. naturalistic learning), medtem ko so učenci, stari med 8 in 10 let ter med 12 in 15 let, najboljše znanje nizozemščine pokazali ob koncu učenja. Učenje je potekalo eno leto. Skupina otrok, starih med 3 in 5 let, pa je pri vseh testih dosegla najslabše rezultate. J1 učencev je bil angleški. Sicer pa je potrebno opozoriti, da običajno prihaja do neustreznega testiranja jezika, saj otroci v predšolskem obdobju drugače usvajajo in tvorijo jezik kot to počno starejši učenci in odrasli. Sicer pa se okno za učenje drugega/ tujega jezika po Blakemore in Frith (2007) nikoli povsem ne zapre.

Loewen in Reinders (2011) ugotavljata, da k dobremu obvladovanju drugega/tujega jezika vodita predvsem čas in trud, vložen v učni proces in ne starost. Robertson (2002) meni, da naj bi bili pri učenju drugega/tujega jezika najbolj vplivni dejavniki (bolj kot starost) motiviranost, stopnja tesnobnosti pri učenju, spretnosti sprejemanja in tvorjenja drugega/tujega jezika ter dejavniki učnega okolja.

Pri mlajših učencih naj bi učenje drugega/tujega jezika temeljilo bolj na specifičnih učnih spretnostih. Starejšim učencem pa verjetno pri učenju drugega/tujega jezika bolj 
pomagajo splošne učne spretnosti. Vendar so verjetno specifične jezikovne spretnosti otroku bolj v pomoč pri učenju drugega/tujega jezika kot odraslim splošne spretnosti. Lahko pa znanje drugega/tujega jezika, ki smo ga pridobili po kritičnem obdobju, sploh ne temelji na prirojenih bioloških strukturah, ki sicer podpirajo učenje prvega ali drugega/tujega jezika $\mathrm{v}$ zgodnjem otroštvu. Starejši začetniki so lahko pri učenju drugega/tujega jezika učinkovitejši, ker si lahko pri pouku pomagajo tudi z metajezikovnim znanjem, strategijami pomnjenja in spretnostmi reševanja problemov (Lightbown in Spada, 2013, str. 93).

Otroci manjšin oziroma priseljencev se pogosto ne morejo izobraževati v svojem J1. Posledično ne razumejo jezika poučevanja, kar učenje drugega/tujega jezika upočasni. Pri učenju drugega/tujega jezika je $v$ tem primeru še toliko bolj potrebno razumevanje učiteljev. Pri omenjenih učencih načelo »čim prej, tem bolje« pri učenju drugega/tujega jezika torej ne velja. Raziskave tudi kažejo, da uspešno učenje drugega/tujega jezika temelji na trdnem znanju J1, kar vključuje tudi pismenost (Lightbown in Spada, 2013, 204-5).

\section{Mit 2: Večina napak, ki jih delajo učenci v drugem/tujem jeziku, nastane zaradi vpliva prvega jezika.}

Napake v drugem/tujem jeziku zagotovo nastajajo tudi zaradi vpliva J1, kar imenujemo prenos/transfer, pogosto tudi medjezikovni vpliv. Ni pa nujno, da je ta vpliv vedno tudi največji. Obstajajo namreč tudi drugi dejavniki, ki vplivajo na pojav napak. Znanje prvega jezika se na katerikoli drug jezik prenaša na kompleksen način (Lightbown in Spada, 2013, str. 224).

Pri pozitivnem transferju gre za prenos znanja iz J1 v drugi/tuji jezik. Do koristnega (pozitivnega) prenosa znanja lahko pride že na začetku učenja drugega/tujega jezika. Učenci namreč lahko imajo zaradi podobnosti prvega in drugega/tujega jezika predznanje, kot na primer skupno abecedo, (večji) del sintakse in besedišče $\mathrm{z}$ istim izvorom. Pri negativnem transferju pa gre za prenos napak, torej neznanja zaradi različnosti dveh jezikov. Negativni transfer je eden izmed ključnih izvorov napak v drugem/tujem jeziku. Te napake je toliko težje odpraviti, kadar je podobnost med $\mathrm{J} 1$ in drugim/tujim jezika le delna. Prav tako odpravljanje napak ovira pogost stik med učenci, ki delajo iste napake (Lightbown in Spada, 2013, str. 205). Napake so lahko tudi posledica želje učencev po tem, da sami raziskujejo ciljni jezik, torej v tem primeru niso posledica transferja (Lightbown in Spada, 2013, str. 206).

Negativni transfer obravnavajo tudi nekateri slovenski avtorji tako na znanstveni kot na strokovni ravni. Transfer med dvema drugima/tujima jezikoma (iz angleščine kot prvega tujega jezika v nemščino kot drugi/tuji jezik) pri slovenskih učencih je tema doktorske disertacije Kač (2015). Analiza pisnih sestavkov učencev nemščine po obdobju treh let potrdi pričakovanja, da se največ transferenc pojavi na ravni besedišča (43\%), manj na glasoslovno-pravopisni (38\%) in najmanj na oblikovno-skladenjski (18\%). Problematiko 
transferja z vidika usvajanja slovničnega časa present perfect pri slovenskih učencih obravnava tudi magistrsko delo Škulj (2015, str. 169). Analiza 300 primerov pisnih sestavkov dijakov dveh generacij med drugim kaže, da se dijaki rabi omenjenega slovničnega časa izogibajo oziroma jo uporabljajo precej manj, kot bi bilo smiselno. Ko pa obliko present perfect uporabijo, to storijo večinoma pravilno, ne glede na to, ali je raba pravilna ali ne. $\mathrm{Z}$ medjezikovnega in medkulturnega vidika je negativni transfer osvetljen v Sešek (2000, str. 256), ki ugotavlja, da bi bilo preučevanje transferja med slovenščino in angleščino potrebno, saj je prav nadstavčna raven tista, kjer se pojavijo največje razlike. Za kontrastivno analizo transferja na besedilni ravni kot največji jezikovni enoti bi bilo nujno tesno sodelovanje anglistične in slavistične stroke. $Z$ vidika nikalnih stavkov negativni transfer preuči Ilc (2005). Transfer iz prvega jezika (slovenščine) v drugi/tuji jezik (angleščino) obravnava tudi Kovačević (2005). Negativni transfer iz slovenščine kot prvega jezika v angleščino kot drugi/tuji jezik je po Berginc (2009, str. 60), ki obravnava jezikovno spretnost pisanje v diplomski nalogi, prisoten v deležu $60 \%$. V okviru teh odstotkov predstavljajo slovnične napake $80 \%$. Podatki temeljijo na analizi 25 esejev iz osnovne šole, srednje šole, gimnazije, srednje poklicne šole in jezikovne šole za odrasle in potrjujejo hipotezo, da je izmed vseh napak največ transfernih na področju slovnice.

\section{Mit 3: Ko učenec naredi napako, jo je potrebno popraviti takoj, da je ne bi utrdil.}

Pretirano popravljanje napak ni samo nekoristno, ampak je lahko celo škodljivo (Truscott, 1996, str. 328).

Tako pri razvijanju prvega jezika kot drugega/tujega jezika velja, da so napake nekaj naravnega, kar drži pri otrocih in odraslih. Iz napak lahko ugotovimo vrzeli v znanju, prekomerno upoštevanje določenega pravila $\mathrm{v}$ drugem/tujem jeziku, neustrezno prenašanje (transfer) vzorcev iz prvega jezika. Razumevanje pojava napak kot nečesa naravnega ne pomeni, da bi moral učitelj vse napake spregledati. Povratna informacija je še posebej potrebna, kadar se napake ponavljajo vztrajno in pri večini učencev. V tem primeru je potrebno pogosto ponavljanje povratne informacije. Učenci lahko povratno informacijo upoštevajo le, če so na to pripravljeni. To pomeni, da so pri drugem/tujem jeziku že na ustrezni razvojni stopnji.

Po drugi strani povratna informacija ne sme biti prepogosta, da ne bi znižala učenčeve motivacije. Za učitelja je pomembno, da opazuje, kako se učenci na povratno informacijo odzivajo. Ustrezna mora biti tudi vrsta povratne informacije (Lightbown in Spada, 2013, str. 208). 


\section{Mit 4: Branje je najboljši način širjenja besedišča.}

Mit toliko bolj drži v primeru učenja besedišča v J1, precej manj pa v primeru učenja drugega/tujega jezika, v katerem običajno beremo manj kot v J1.

\section{Kratek pregled raziskovanja besedišča}

V 70. in zgodnjih 80. letih je raziskovalce drugega/tujega jezika bolj zanimalo preučevanje skladnje in oblikoslovja kot raziskovanje pridobivanja besedišča. Paul Meara (1980) je označil učenje besedišča kot »zanemarjen vidik učenja jezika« (Lightbown in Spada, 2013, str. 60). Da bi razširili znanje o jezikovnih univerzalijah in usvajanju jezika, so znanstveniki preučevali vzorce napak (Wode, 1981) in stopnje razvijanja jezika (Bloom, 1991). Nato je tudi preučevanje pridobivanja besedišča zavzelo pomembnejše mesto v raziskavah.

Veliko raziskav odgovarja na raziskovalno vprašanje, kako pridobiti besedišče, ki bo zadostovalo za uspešno sporazumevanje v različnih okoliščinah. Usvojiti že osnovno besedišče v drugem/tujem jeziku je za učenca zahtevna naloga. Odrasla, izobražena angleško govoreča oseba naj bi namreč za vsakdanje sporazumevanje uporabljala okoli 2000 besed, medtem ko naj bi jih poznala okoli 20000 (Lightbown in Spada, 2013, str. 61).

Vidike razpoložljivosti besedišča (leksikalne razpoložljivosti), ki so pomembni pri usvajanju besedišča v drugem/tujem jeziku, predstavi Marjana Šifrar Kalan (2015), ki se tudi sicer ukvarja z raziskovanjem usvajanja besedišča.

\section{Kako se otroci učijo besedišča v prvem jeziku?}

V J1 se otroci naučijo od nekaj sto do tisoč in več besed na leto, odvisno predvsem od tega, koliko in kaj berejo (Nagy, Herman in Anderson, 1985). Besedišče, potrebno za uspešno delo v šoli, pridobijo tako z obveznim branjem (predpisanim v šoli) kot branjem za zabavo umetnostnih in neumetnostnih besedil (Lightbown in Spada, 2013, str. 14). Stephen Krashen (1989) meni, da je najboljši vir širjenja besedišča branje za zabavo (Lightbown in Spada, 2013, str. 63). Gardner (2004) ugotavlja, da je za uspešno širjenje besedišča nujno branje različnih vrst besedil, saj se določeno besedišče pojavlja le v posamezni vrsti besedila. Lightbown in Spada (2013, str. 206) pa ugotavljata, da učenci pridobijo največ besedišča z branjem besedil, ki se jim zdijo zanimiva in uporabna.

Branje je tudi v drugem/tujem jeziku način širjenja besedišča, vendar je težje kot v prvem jeziku. Poleg tega otroci v drugem/tujem jeziku običajno berejo (precej) manj kot v prvem (Lightbown in Spada, 2013, str. 206; Nation, 2001; Nation 2007).

\section{Kaj sploh pomeni znati besedo?}

Prvi korak k znanju besede je razlikovanje med besedo in ne-besedo. Če zapišemo drugače, gre za prepoznavanje besede. Prav to testira Meara (2005) s pomočjo seznama besed 
in ne-besed. Nadaljnji koraki k čim boljšemu znanju besede so prepoznavanje njenega pomena $\mathrm{v}$ znanem sobesedilu, razlaga $\mathrm{z}$ definicijo ali prevodom, iskanje ustreznih asociacij, prepoznavanje njenih delov, dopolnjevanje povedi, tvorba nove povedi, metaforična uporaba besede, razumevanje enakozvočnice (homonima) kot tudi poznavanje izvora besede (Lightbown in Spada, 2013, str. 64).

\section{Vloga konteksta pri učenju novih besed}

Nove besede moramo spoznavati (videti, slišati) v sobesedilu. To sobesedilo ne sme biti prezahtevno, če naj iz njega razberemo pomen novih besed (Lightbown in Spada, 2013, str. 63).

Besedo resnično povežemo z njenim pomenom šele, ko jo srečamo večkrat, po ugotovitvah Nationa (2001) šestnajstkrat. Spoznati besedo na smiseln način pomeni, da jo vidimo, slišimo in razumemo. Številka je še večja, če želimo besedo uporabiti v tekočem govoru ali si dovolj hitro priklicati njen pomen pri branju v novem kontekstu. Pri tekočem branju in govoru moramo namreč razumeti večino besed brez osredotočanja na njihov pomen. Med branjem sicer lahko pomen besed tudi ugibamo iz besedila, vendar mora besedilo vsebovati vsaj 95 odstotkov znanih besed (Hu in Nation, 2000).

\section{Vloga pouka pri širjenju besedišča}

Hulstijn in Laufer (2001) ugotavljata, da besedišče lahko širimo hitreje, če sodelujemo $\mathrm{v}$ aktivnostih pri pouku, pri katerih se na nove besede osredotočimo in jih uporabimo v nalogah produktivnega tipa. Kojić-Sabo in Lightbown (1999) ugotavljata, da je učenje besedišča učinkovitejše, če vanj vložimo napor in uporabljamo učinkovite učne strategije. Te so pisanje zapiskov, iskanje besed v slovarju in utrjevanje novega besedišča. Besedišča pa se lahko učimo tudi izven razreda (Zimmerman, 2009).

Sledi primer učenja in poučevanja drugega/tujega jezika, ki je potekalo zgolj pri pouku. Pristopu k učenju drugega/tujega jezika zgolj s poslušanjem in/ali branjem (Krashen 1985, 1989) je bil poskusno uporabljen v razredu učencev, starih med 8 in 10 let, $v$ francosko govorečem delu Kanade (Lightbown, Halter, White in Horst, 2002; Trofimovich, Lightbown, Halter in Song, 2009). Krashenov pristop temelji na hipotezi, da se jezika lahko učimo oziroma ga usvajamo tudi samo s poslušanjem in/ali branjem. Jezikovni vnos (ang. language input) mora biti razumljiv. Glede na to hipotezo drugega/tujega jezika sploh ni potrebno uporabljati (govoriti in pisati), če se ga želimo naučiti. Potekalo je tudi poučevanje druge skupine učencev po standardnem programu. V poskusni skupini so se učenci pri pouku angleščine kot drugem/tujem jeziku učili samo s poslušanjem in branjem $\mathrm{v}$ angleščini, medtem ko je $\mathrm{v}$ skupini s standardnim programom pouk potekal pretežno po slušnojezikovnem pristopu. Pouk je v obeh skupinah potekal po pol ure na dan dve leti. Primerjava med poskusnim in standardnim programom je pokazala, da je bilo znanje udeležencev po dveh letih učenja $v$ obeh skupinah podobno ne samo pri razumevanju (receptivni rabi), pač pa tudi pri govoru (produktivni rabi). V skupini s poskusnim programom so nekateri udeleženci znali celo več kot udeleženci standardnega programa. Ponovni test po nadaljnjih treh letih je pokazal, da se skupini v znanju drugega/tujega 
jezika nista veliko razlikovali pri razumevanju in nekaterih postavkah govora. Udeleženci standardnega programa pa so dosegli boljše rezultate pri pisanju kot udeleženci poskusnega programa. Ti učenci so po dveh letih nadaljevali s standardnim programom, ki pa je poleg slušnojezikovnega pristopa vključeval tudi govor in pisanje, učiteljevo povratno informacijo in sodelovanje med sošolci.

Naslednji primer ponazarja pristop k poučevanju in učenju drugega/tujega jezika $\mathrm{z}$ branjem tako pri pouku kot izven šole. V raziskavi (Horst, 2005) je bilo udeleženih 21 odraslih priseljencev v Kanadi, vključenih v pouk angleščine kot drugega/tujega jezika. Po šestih tednih branja prilagojenega čtiva iz razredne knjižnice so nadaljevali z branjem istega čtiva doma. Njihov obseg besedišča se je po branju povečal, kar je bilo dokazano s posebej razvitim instrumentom za merjenje razumevanja besedišča. Za znatnejši napredek pa bi bilo potrebno prebrati več kot le eno ali dve knjižici na polletje (v Lightbown in Spada, 2013, str. 161).

Marjana Šifrar Kalan v prispevku na konferenci (2015) predstavi vidike razpoložljivosti besedišča (leksikalne razpoložljivosti), ki so pomembni pri usvajanju besedišča v drugem/tujem jeziku.

Kako hitro bomo širili besedišče in koliko bo to znanje poglobljeno, je torej odvisno od številnih dejavnikov, med drugim od tega, koliko beremo, vrste in zahtevnosti besedil, (ne)umeščenosti besedišča $v$ sobesedilo, učenja $\mathrm{v}$ jezikovnem programu ali izven njega, sodelovanja v vlogi udeležencev pri pouku, vrste nalog, pristopa k poučevanju drugega/ tujega jezika ter znanja o tem, kaj vse pomeni znati besedo. Mit, da je branje najboljši način širjenja besedišča, tudi praviloma bolj drži za J1 kot za drugi/tuji jezik.

\section{3}

\section{ZAKLJUČEK}

Uporabniki tujih jezikov (tudi učitelji) se srečujemo s številnimi miti o učenju tujega jezika. Pomembno je, da se jih zavedamo in njihovo resničnost preverjamo, še posebej, če se morda zdijo samoumevni, saj pomembno usmerjajo poučevanje. Za ponazoritev takšnega razmisleka so bili na podlagi temeljne literature tega članka izbrani štirje miti od osemnajstih, ki veljajo za zelo razširjene. Za prvi mit lahko ugotovimo, da drži le pogojno. Čim zgodnejši začetek učenja tujega jezika ne pomeni nujno tudi večji končni napredek v obvladovanju jezika. Za drugi mit lahko zaključimo, da je prenos jezikovnega neznanja oziroma negativni transfer zagotovo pomemben vir napak v tujem jeziku tudi v primeru slovenščine kot J1 in angleščine kot drugega/tujega jezika. Potrebne pa bi bile dodatne raziskave ne samo manjših, slovničnih jezikovnih enot, pač pa tudi besedilnih. Napake so včasih posledica samostojnega raziskovanja tujega jezika. Za tretji mit, ki trdi, da je potrebno vsako napako takoj popraviti, da je učenci ne bi utrdili, lahko ugotovimo, da je zapisan prestrogo. Popravljati je potrebno predvsem napake, ki se pri ponavljajo pri večini učencev. Učitelji naj bi tudi razmislili o ustreznosti povratne informacije. Napako sicer lahko razumemo tudi kot 
naraven korak v razvoju jezika. Četrti mit, da je branje najboljši način širjenja besedišča, lahko v veliki meri potrdimo. Opozorili pa bi na pomen izbire ustreznih besedil pri pouku, spodbujanja $\mathrm{k}$ branju $\mathrm{v}$ drugem/tujem jeziku, obravnavanje novega besedišča $\mathrm{v}$ sobesedilu, kar je le nekaj dejavnikov, ki vplivajo na hitrost širjenja besedišča. S člankom sva avtorici poskušali doprinesti k refleksiji o resničnosti obravnavanih mitov o učenju drugega/tujega jezika. Meniva, da je takšen razmislek lahko koristen za vse uporabnike drugega/tujega jezika ne glede na to, na kateri izobraževalni ravni delujejo.

\section{LITERATURA}

BERGINC, Tanja (2009) Negative transfer of the mother tongue in EFL writing of Slovenian learners (Diplomska naloga iz Didaktike angleškega jezika). Filozofska fakulteta, Ljubljana.

BLAKEMORE, Sarah-Jane/Uta FRITH (2007) The learning brain. Oxford: Blackwell Publishing.

BLOOM, Lois (1991) Language Development from Two to Three. Cambridge: Cambridge University Press.

CAROLL, John (1991) Cognitive abilities in foreign language aptitude: Then and now. V T. Parry in C. Stansfield (ur.), Language Aptitude Reconsidered. Englewood Cliffs, NJ: Prentice hall.

European Commission (2012) First European Survey on Language Competences. Executive Summary. Pridobljeno 21. 11. 2016 s http://www.surveylang.org/media/ExecutivesummaryoftheESLC_210612.pdf

GARDNER, Dee (2004) Vocabulary input through extensive reading: A comparison of words found in children's narrative and expository reading materials. Applied Linguistics, 25(1), 1-37.

HORST, Marlise (2005) Learning L2 vocabulary through extensive reading: A measurement study. Canadian Modern Language Review, 61(3), 355-82.

HU, Marcella/NATION, I. S. Paul (2000) Unknown vocabulary density and reading comprehension. Reading in a Foreign Language, 13(1), 403-30.

HULSTIJN, Jan/LAUFER, Batia (2001) Some empirical evidence for the involvement load hypothesis in vocabulary acquisition. Language Learning, 51(3), 539-58.

ILC, Gašper (2005) I think he will not be happy until she does not come: negative transfer of expletive and raised negation. V The future(s) of English studies?, Alpine-Adriatic-Anglistics [Conference], Klagenfurt, November, 3rd-5th 2005, 4. Klagenfurt: Alpen-Adria-University.

KAČ, Liljana (2015) Transference iz angleščine v nemških sestavkih slovenskih učencev (Doktorska disertacija). Filozofska fakulteta, Maribor. Pridobljeno 19. 11. $2016 \mathrm{~s}$ https://dk.um.si/IzpisGradiva.php?id=48214 
KOJIĆ-SABO, Izabella/LIGHTBOWN, Patsy (1999) Students' approaches to vocabulary learning and their relationship to success. Modern Language Journal, 83(2), 176-92. KOVAČEVIĆ, Milena (2005) Transfer materinskoga jezika u učenju stranoga jezika: slovensko-engleski slučaj. Strani jezici, 34(3), 235-243.

KRASHEN, Stephen (1985) The Input Hypothesis: Issues and Implications. London: Longman.

KRASHEN, Stephen (1989) We acquire vocabulary and spelling by reading: Additional evidence for the input hypothesis. Modern Language Journal, 73(4), 440-64.

LENNEBERG, Eric (1967) Biological Foundations of Language. New York: Academic Press.

LESNIČAR, Barbara (ur.). (2016) Učni načrt. Program osnovna šola. Angleščina. Pridobljeno 21. 11. $2016 \mathrm{~s}$ http://www.mizs.gov.si/fileadmin/mizs.gov.si/pageuploads/ podrocje/os/prenovljeni_UN/UN_anglescina.pdf

LIGHTBOWN, Patsy/SPADA, Nina (2013) How languages are learned. Oxford: Oxford University Press.

LIGHTBOWN, Patsy (2008) Easy as pie? Children learning languages. Concordia Working Papers in Applied Linguistics, 1, 1-25.

LIGHTBOWN, Patsy/HALTER, R./WHITE, J.L./HORST, M. (2002) Comprehension-based learning: The limits of »do-it-yourself«. Canadian Modern Language Review, 58(3), 427-64.

LOEWEN, S./REINDERS, H. (2011) Key Concepts in Second Language Acquisition. New York: Palgrave Macmillan.

MEARA, Paul (2005) Designing vocabulary tests for English, Spanish and other languages. V C. Butler, M. dos Angeles Gomez-Gonzales in S. Doval-Suarez (ur.), The Dynamics of Language Use: Functional and Dynamic Perspectives. Amsterdam: John Benjamins. Pridobljeno 19. 11. $2016 \mathrm{~s}$ http://www.lognostics. co.uk/tools/

MEARA, Paul (1980) Vocabulary Acquisition: A neglected aspect of language learning. Language Teaching and Linguistics Abstracts, 13, 221-46.

NAGY, W. E./HERMAN, P. A./ANDERSON, R. (1985) Learning words from context. Reading Research Quarterly, 20(2), 233-53.

NATION, Paul (2001) Learning Vocabulary in Another Language. Cambridge: Cambridge University Press.

NATION, Paul (2007) The four strands. Inovation in Language Learning and Teaching, $1(1), 1-12$.

PAŠIĆ, Mersiha (2009) Attitudes to error: error gravity and error correction. Diplomska naloga iz Didaktike angleškega jezika. Ljubljana: Filozofska fakulteta.

PATKOWSKI, Mark (1980) The sensitive period for the acquisition of syntax in a second language. Language Learning, 30(2), 449-72. 
PEVEC SEMEC, Katica (ur.) (2013a) Učni načrt. Program osnovna šola. Tuji jezik v 1. razredu. Pridobljeno 21. 11. $2016 \mathrm{~s} \mathrm{http://www.mizs.gov.si/fileadmin/mizs.gov.}$ si/pageuploads/podrocje/os/devetletka/program_razsirjeni/TJ_prvi_razred_izbirni_neobvezni.pdf

PEVEC SEMEC, Katica (ur.) (2013b) Učni načrt. Program osnovna šola. Tuji jezik v 2. in 3. razredu. Pridobljeno 21. 11. $2016 \mathrm{~s} \mathrm{http://www.mizs.gov.si/fileadmin/mizs.}$ gov.si/pageuploads/podrocje/os/prenovljeni_UN/UN_TJ_2._in_3._razred_OS.pdf

ROBERTSON, Paul (2002) The critical age hypothesis. A critique of research methodology. V P. Robertson, P. Dash in J. Jung (ur.), The Asian EFL Jornal Quarterly, 4(1), 4-25.

SEŠEK, Urška (2000) Medjezikovni in medkulturni transfer: vplivi med angleščino in slovenščino v pisni rabi. V I. Štrukelj (ur.), Kultura, identiteta in jezikv vrocesih evropske integracije, 1, 248-257. Ljubljana: Društvo za uporabno jezikoslovje Slovenije.

SNOW, Catherine E./HOEFNAGEL-Höhle, Marian (1978) The Critical Period for Language Acquisition: Evidence from Second Language Learning. Child Development, 49(4), 1114-1128. Pridobljeno 20. 11. 2016 s http://www.kennethreeds.com/uploads/2/3/3/0/2330615/article.pdf

SVET EVROPE. (2011). Skupni evropski jezikovni okvir: učenje, poučevanje, ocenjevanje. Pridobljeno 19.11.2016 s http://www.mizs.gov.si/si/delovna_podrocja/urad_za razvoj_izobrazevanja/jezikovno_izobrazevanje/skupni_evropski_jezikovni_okvir/

ŠIFRAR-KALAN, Marjana (2015) Lexical availability and L2 vocabulary acquisition [Elektronski vir]. VA. Akbarov (ur.), Linguistics, culture and identity in foreign language education, FLTAL'14, maj 9-10, 2014, Sarajevo, BIH, 1249-1256. Sarajevo: International Burch University. Pridobljeno 19. 11. 2016 s https://flal.ibu.edu.ba/ assets/fltal/userfiles/documents/Proceeding-Book-(Version1.2).pdf

ŠKULJ, Irena (2015) Težave slovenskih dijakov pri usvajanju Present Perfecta v anglešcini (Magistrsko delo). Ljubljana: Filozofska fakulteta.

TROFIMOVICH, P./LIGHTBOWN, P.M./HALTER, H.R./SONG, H. (2009) Comprehension-based practice: The development of L2 pronunciation in a listening and reading program. Studies in Second Language Acquisition, 31(4), 609-39.

TRUSCOTT, John (1996) The case against grammar correction in L2 writing classes. Language Learning, 46(2), 327-369.

WODE, Henning (1981) Language acquisition universals: A unified view of language acquisition. V H. Winitz (ur.), Native Language and Foreign Language Acquisition. Annals of the New York Academy of Sciences, 379, 218-34. New York: New York Academy of Science.

ZIMMERMAN, Cheryl Boyd (2009) Word Knowledge: A Vocabulary Teacher's Handbook. Oxford: Oxford University Press. 


\section{POVZETEK}

O učenju tujih jezikov obstajajo določeni miti, nepreverjene »resnice«, ki so se ponekod »fosilizirali« in morda sploh več ne vzbujajo nobenih dvomov med običajnimi uporabniki jezikov. V članku osvetlimo izbor štirih mitov o učenju drugega/tujega jezika. V prvem mitu se sprašujemo, kakšno vlogo ima starost pri učenju drugega/tujega jezika. V drugem mitu se sprašujemo, če večina napak v drugem/tujem jeziku res nastane zaradi prenosa (ne)znanja iz prvega jezika v drugi/ tuji jezik oziroma transferja. S tretjim mitom preverjamo, ali naj res učitelj vsako napako popravi takoj z namenom, da si je učenec ne bo zapomnil. V četrtem mitu pa nas zanima, ali ima branje res največji vpliv na širjenje besedišča tako v prvem kot drugem/tujem jeziku. Miti o učenju tujega jezika so pogosto kompleksni, kar velja tudi za mite, predstavljene v tem članku. Glede njihove resničnosti ugotavljamo, da najverjetneje najmanj drži mit o nujnosti takojšnjega popravljanja napak, precej bolj pa prvi, drugi in četrti mit.

Ključne besede: drugi/tuji jezik, miti o učenju drugega/tujega jezika, zgodnji začetek, transfer, učenje besedišča preko branja, popravljanje napak

\section{ABSTRACT}

\section{Myths about second language learning}

There exist several myths about second/foreign language learning. Many of them might have been »fossilised « by second/foreign language users. The article highlights a selection of four myths on second/foreign language learning. Myth 1 is that the sooner one starts to learn a second/foreign language, the better they will learn it. Myth 2 is that transfer from L1 is the major source of errors in a second/foreign language. Myth 3 is that the teacher should correct errors as soon as they appear to prevent the student from remembering them. Myth 4 is that the best way to learn new vocabulary is through reading. Finally we conclude that myths on second/foreign language acquisition are complex, which is true for the myths presented in this paper, too. The least plausible seems to be myth 3 about the urgency of immediate correction of errors. Myths 1,2 and 4 seem to be true, although with certain limitations.

Keywords: second/foreign language, myths about second language learning, early start, transfer, learning vocabulary through reading, error correction 